\title{
UV curable cross-linked polymer and polymer-inorganic materials for fuel cell application
}

Mariia Zhyhailo $^{1}$, Khrystyna Rymsha ${ }^{1}$, Iryna Yevchuk ${ }^{1}$, Oksana Demchyna ${ }^{1}$, Victoria Kochubei ${ }^{2}$

1. Department of Physical Chemistry of Fossil Fuel InPOOC NAS of Ukraine, UKRAINE, Lviv, Naukova Str., 3a E-mail: zhyhailo.mariia@gmail.com

2. National Lviv Polytechnic University, UKRAINE, Lviv, S. Bandera Str., 12 E-mail: vicvitkoch@ gmail.com

Proton conductive cross-linked membranes (polyacrylate copolymer and polyacrylate-silica nanocomposites) were synthesized by $U V$ initiated polymerization in situ. Proton conductivity of membranes, investigated by impedance spectrometry, was found to be sufficiently high. Contact angle measurements allow to estimate free surface energy of synthesized membranes. The membranes also exhibit good thermal stability.

Keywords - fuel cell, alternative energy source, proton conductive membrane, organic-inorganic material, acrylate, sol-gel precursor

\section{Introduction}

A great progress in energy consumption during the last years causes increasing need in alternative energy sources [1]. One of the most promising energy sources are hydrogen and alcohols (mainly methanol), which are used as fuel in fuel cells. However, fuel cell technology needs to be improved significantly for practical realization and commercialization. In particular the creation of high effective proton exchange membranes is of a great interest as PEM determines the efficiency of the whole device.

The most commonly used are Nafion membranes which have excellent chemical stability and high proton conductivity. At the same time they suffer from methanol crossover and dehydratation at high temperaturers. So, new PEMs such as sulfonated aromatic membranes, graft membranes, blend membranes have been recently proposed and intensely investigated. Among different approaches UV curing seems to be suitable as this technique provides high reaction rate as well as the possibility to obtain thin films.

\section{Results and discussion}

Cross-linked copolymer membranes were prepared from the mixture of acrylic monomers, namely acrylonitrile (35 wt. \%), acrylic acid (15 wt. \%), 3-sulfopropyl acrylate potassium salt (25 wt. \%) and cross-linker ethyleneglycol dimethacrylate (25 wt. \%) by UV initiated polymerization (photoinitiator DMPA). Polymer-inorganic membranes were prepared from the same monomers and sol-gel system (SGS : TEOS - ethanol - water) using UV initiated polymerization in situ. The content of the added sol-gel system (wt. \%) in membrane samples was as follows: $\mathrm{S} 1-0 ; \mathrm{S} 2-1$; $\mathrm{S} 3-3 ; \mathrm{S} 4-5 ; \mathrm{S} 5$ - 7.

Gel fractions of all the samples of the obtained membranes were high (>95\%). Membranes were converted to $\mathrm{H}^{+}$ionic form by immersion in $\mathrm{HCl} 0.1 \mathrm{M}$ for $24 \mathrm{~h}$.

Contact angle measurements using 2 liquids allow to estimate free surface energy and its components (dispersive and hydrogen ones) of the obtained membranes. The introducing of solgel system into the polymerizing formulations leads to hydrophobization of membrane surface and decreasing of the free surface energy. The results of the calculations using the known Owens-Wendt equation are summarized in Table 1. 
Values of contact angel measurement and free energy of membrane surface

\begin{tabular}{|c|c|c|c|c|c|c|}
\hline $\mathrm{N}$ & Sample & $\begin{array}{c}\theta, \text { degree } \\
\mathrm{C}_{3} \mathrm{H}_{8} \mathrm{O}_{3}\end{array}$ & $\begin{array}{c}\theta, \text { degree } \\
\mathrm{CH}_{2} \mathrm{I}_{2}\end{array}$ & $\begin{array}{c}\lambda_{\mathrm{s}}{ }^{\mathrm{d}}, \\
\mathrm{mN} / \mathrm{m}\end{array}$ & $\begin{array}{c}\lambda_{\mathrm{s}}{ }^{\mathrm{w}}, \\
\mathrm{mN} / \mathrm{m}\end{array}$ & $\begin{array}{c}\lambda_{\mathrm{s}}, \\
\mathrm{mN} / \mathrm{m}\end{array}$ \\
\hline 1 & $\mathrm{~S} 1$ & 43,9 & 39,5 & 31,09 & 16,54 & 47,63 \\
\hline 2 & $\mathrm{~S} 2$ & 39,8 & 37,1 & 31,56 & 18,21 & 49,77 \\
\hline 3 & $\mathrm{~S} 3$ & 40,2 & 36,9 & 31,70 & 18,01 & 49,71 \\
\hline 4 & $\mathrm{~S} 4$ & 42,6 & 35,2 & 32,16 & 17,16 & 49,24 \\
\hline 5 & $\mathrm{~S} 5$ & 43,7 & 34,9 & 32,24 & 16,84 & 49,08 \\
\hline
\end{tabular}

As one can see the sample S2 (containing $1 \%$ added SGS) shows the increase of the hydrogen component of free surface energy, total free surface energy also increases. For the sample S5 (7 \% of the added SGS) free surface energy is a bit less than for the sample S2, but it is larger than for the sample without the added SGS. So, silica component promotes water retention.

Proton conductivity of the synthesized membranes, measured by impedance spectrometry at $20^{\circ} \mathrm{C}$, is presented in Table 1 . The values of proton conductivity are relatively high $\left(10^{-4}-10^{-2}\right.$ $\mathrm{Sm} / \mathrm{cm})$.

Table 2

\begin{tabular}{|c|c|c|c|c|c|}
\hline Sample & $\mathrm{S} 1$ & $\mathrm{~S} 2$ & $\mathrm{~S} 3$ & $\mathrm{~S} 4$ & $\mathrm{~S} 5$ \\
\hline$\sigma, \mathrm{Sm} / \mathrm{cm}$ & $3.53 \cdot 10^{-4}$ & $1.37 \cdot 10^{-2}$ & $1.01 \cdot 10^{-3}$ & $9.70 \cdot 10^{-4}$ & $9.27 \cdot 10^{-4}$ \\
\hline
\end{tabular}

Thermal behaviour of membranes was investigated by thermogravimetric method (Fig.1).

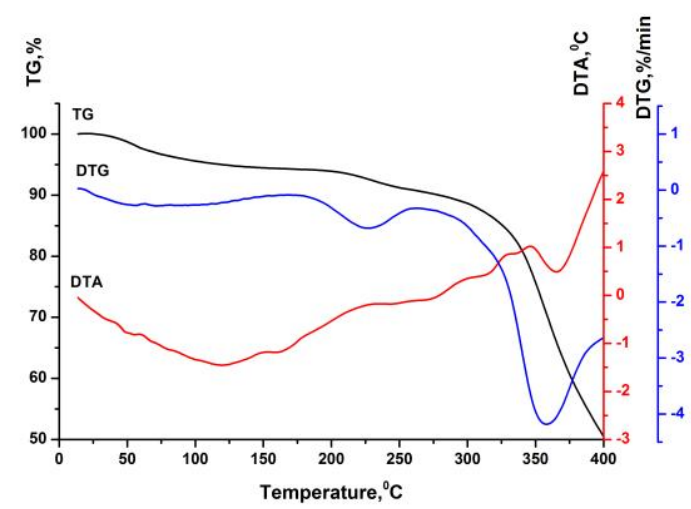

Fig.1. Thermogram for the sample S1

The presence of the inorganic component in membrane leads to the increase in thermal stability - decomposition of sulfo groups in polyacrylic-silica membranes takes place at higher temperatures.

\section{Conclusion}

The synthesized polyacrylic and polyacrylic-silica membranes have high proton conductivity and thermal stability. The adding of TEOS-based sol-gel system promotes water retention and thermal stability. The materials are attractive as proton conductive membranes for fuel cell application.

\section{References}

[1] S. Shamim, K. Sudhakar, B. Choudhary, J. Anwar. "A review on recent advances in proton exchange membrane fuel cells: Materials, technology and applications", Advances in Applied Science Research, vol. 6, no. 9, 2015, pp. 89-100. 